Article

\title{
Synthesis and Characterization of a New Nanocomposite Film Based on Polyvinyl Alcohol Polymer and Nitro Blue Tetrazolium Dye as a Low Radiation Dosimeter in Medical Diagnostics Application
}

\author{
Saleh Alashrah ${ }^{1}\left(\mathbb{D}\right.$, Yassine El-Ghoul ${ }^{2,3, *}$ and Mohammed Ahmed Ali Omer ${ }^{4} \mathbb{D}$ \\ 1 Department of Physics, College of Science, Qassim University, Buraidah 51452, Saudi Arabia; \\ ashrh@qu.edu.sa \\ 2 Department of Chemistry, College of Science, Qassim University, Buraidah 51452, Saudi Arabia \\ 3 Textile Engineering Laboratory, University of Monastir, Monastir 5019, Tunisia \\ 4 Department of Radiologic Technology, College of Applied Medical Sciences, Qassim University, \\ Buraidah 51452, Saudi Arabia; ma.omer@qu.edu.sa \\ * Correspondence: y.elghoul@qu.edu.sa
}

check for updates

Citation: Alashrah, S.; El-Ghoul, Y.; Omer, M.A.A. Synthesis and Characterization of a New

Nanocomposite Film Based on Polyvinyl Alcohol Polymer and Nitro Blue Tetrazolium Dye as a Low Radiation Dosimeter in Medical Diagnostics Application. Polymers 2021, 13, 1815. https://doi.org/ $10.3390 /$ polym 13111815

Academic Editor: Haw-Ming Huang

Received: 23 April 2021

Accepted: 27 May 2021

Published: 31 May 2021

Publisher's Note: MDPI stays neutral with regard to jurisdictional claims in published maps and institutional affiliations.

Copyright: (c) 2021 by the authors. Licensee MDPI, Basel, Switzerland. This article is an open access article distributed under the terms and conditions of the Creative Commons Attribution (CC BY) license (https:// creativecommons.org/licenses/by/ $4.0 /)$

\begin{abstract}
Dosimetry is a field of increasing importance in diagnostic radiology. There has been a realization among healthcare professionals that the dose of radiation received by patients via modern medical X-ray examinations could induce acute damage to the skin and eyes. The present study highlights the synthesis of polyvinyl alcohol/nitro blue tetrazolium nanocomposite films (PVA/NBT) for radiation detection depending on chromic, optical, chemical and morphologic changes. First, we synthesized the nanocomposite film-based PVA doped with NBT and the different parameters of the preparation procedure were optimized. Then The films were exposed to different low X-ray doses on the scale of mGy level $(0,2,4,10$ and $20 \mathrm{mGy})$. The sensitivity and the performance of the made composite films were evaluated via different characterization methods. Indeed, the response curve based on UV-Vis absorptions revealed a linear increase in absorbance with increased radiation doses $(\mathrm{R}=0.998)$. FTIR analysis showed a clear chemical modification in recorded spectra after irradiation. X-ray diffraction assessment revealed clear structural changes in crystallinity after ionization treatment. SEM analysis showed a clear morphological modification of PVA/NBT films after irradiation. In addition, the prepared PVA/NBT films exhibited excellent pre- and postirradiation stability in dark and light. Finally, the quantitative colorimetry study confirmed the performance of the prepared films and the different colorimetric coordinates, the total color difference $(\triangle \mathrm{E})$ and the color strength $(\mathrm{K} / \mathrm{S})$ showed a linear increase with increasing $\mathrm{X}$-ray doses. The made nanocomposite PVA/NBT film might offer promising potential for an effective highly sensitive medical dosimeter applied for very low doses in X-ray diagnostic radiology.
\end{abstract}

Keywords: polyvinyl alcohol; nitro blue tetrazolium; nanocomposite film; characterization; Xradiation dosimeter; medical diagnostic radiology

\section{Introduction}

The second half of the 20th century has experienced an extraordinary industrial trend of polymer materials in all the sectors of industrial activity. Nowadays, although polymer production is continuously growing, all developed countries face new challenges regarding the development of a new generation of functional polymers-so-called smart polymers-having a vital vocation related mainly to the most important field of medicine and health [1-5]. Development and innovation in the fabrication of dosimeters are crucial factors for monitoring radiation exposure. Recently studied polymer nanocomposite materials for dosimeters comprise a matrix and a coloring agent [6-8]. Different dosimeters such as ionization chamber dosimeters, thermoluminescent dosimeters (TLDs), metal oxide 
semiconductor field-effect transistors (MOSFETs), films (radiographic or gafchromic), 2D array (pixel ionization chambers or diodes) and electronic portal imaging device (EPID) have been developed for radiation detection [9]. An ideal dosimeter has some basic features that make it suitable for measurements [10-12]. Among these basic features are reproducibility and accuracy. In fact, in dosimetry, the uncertainty related to the measurement is frequently expressed in terms of reproducibility and accuracy. High reproducibility is associated with a small standard deviation in the distribution of the results in the measurements. Reproducibility includes systematic errors in a dosimetry device, electrometer leakage and repeated measurements. The accuracy is the ability of the dosimeter to measure the delivered dose correctly and it matches the true value of the measured dose. In addition, absolute dose determination is also an important feature. An ideal dosimeter should measure the absolute dose (Gy) rather than the relative dose $(\%)$. Normalization procedure can be used to convert relative dose to absolute dose [13]. Furthermore, an ideal dosimeter response is independent of the orientation of irradiation. This requirement is ideally met if the dosimeter is tissue-equivalent and circular in shape [14]. An ideal dosimeter should also have a linear response with either the dose or the dose rate. This is important when beaten high-energy linear accelerators are used because the delivery of high-dose beats of radiation should be in short time periods. An ideal dosimeter must be independent of the field size. In addition, the response of the dosimeter should be constant when varying energies of the incident beam [15]. The smallest change in response of the dosimeter against radiation energy generally means that an effective atomic number of the dosimeter is close to the tissue [16]. Spatial resolution is also considered a desired feature. Since the dose is a point quantity, the dosimeter must be able to determine the dose from a very small volume [17]. Practically, all dosimeters have a finite size and they can provide inaccurate readings of delivered dose in high dose gradients such as the penumbral regions [18]. An ideal dosimeter must have the shortest detection time possible and the response should show the measured dose immediately after radiation, without generating any toxic hazards. Furthermore, an ideal detector must present a reasonable cost, be simple to use and be materially strong enough for clinical practice on a tedious basis without any physical limitations [14].

Evidently, all these characteristics cannot be accomplished by all dosimeters. Therefore, for the importance of the choice of the dosimeter as well as its reader, we must take into account the conditions of measurement. Some physical characteristics of an ideal dosimeter listed above have been studied for dosimeters such as gafchromic films and polymers detectors used in treatment verification or diagnostics [19-21].

Synthetic polymers can be synthesized with a broad variety of structures and appropriate physical and chemical properties. The increasing interest related to the design of this kind of polymers is explained by their use in a wide range of biomedical applications as diverse as tissue engineering, drug delivery, therapeutics, diagnostics, and so on [22-26]. Over the last decade, the methods for the synthesis of polymers, processing, and characterization have been developing rapidly, which brings both challenges and opportunities to design novel polymeric bio-materials [27-31].

Moreover, the hybridization of synthetic polymers by metal nanoparticles and specific selected organic dyes have been considered as a key function for the wider applications of polymer nanocomposites recently [32-34]. The importance of doping the polymers with selective materials can be attributed to improving the chemical and physical properties which in turn enhance the utilization of the final product in electronics, biomedical engineering, displays, physics and biosensors $[35,36]$. In the same realm, the doping of polymers with organic dye or compound also could induce desirable characteristics to the final products which in turn widens the applications in the field of radiation detection, measurement and biosensors.

The aim of the current study was to synthesize indigenous nanocomposite films made of PVA/NBT dye to be investigated as low radiation detection dosimeters. Preparing an efficient dosimeter for low radiation levels applied in diagnostic radiology is a veritable 
challenge nowadays, especially since there are no previously performed studies on using NBT for PVA film dosimetry in mGy dose levels. Firstly, we synthesized PVA/NBT film labels and the parameters of their preparation process were optimized. Then, the prepared films were irradiated with different $X$-ray doses $(0,2,4,10$ and $20 \mathrm{mGy})$. The non-irradiated films and those exposed at different radiation doses were then characterized by different chemical, physical, colorimetrical and morphological techniques (UV, FTIR, densitometry, colorimetry, XRD and SEM). The comparison of the responses to the increasing doses received by irradiated PVA/NBT films via the different characterizations would be decisive in the evaluation of the performance of the nanocomposite films produced as radiation dosimeters applied in the field of X-ray diagnostic radiology.

\section{Experimental}

\subsection{Materials}

Polyvinyl alcohol (Degree of hydrolysis: $85-90 \%$ and MW: 85,000-124,000) polymer used as a matrix in the nanocomposite film and nitro blue tetrazolium chloride (C40H30 $\mathrm{Cl} 2 \mathrm{~N} 10 \mathrm{O} 6 . \mathrm{H} 2 \mathrm{O} . \mathrm{CH} 4 \mathrm{O} ; \mathrm{MW}=867.70$ ) investigated in the development of the different film dosimeters was purchased from Sigma Aldrich (St. Louis, MO, USA). Ultrapure (Millipore) water (Milli-Q ${ }^{\circledR}$ Direct, purified through a QPAK ${ }^{\circledR}$ cartridge, Darmstadt, Germany), was used for the synthesis of the film dosimeter. All the used reagents were procured of analytical grade and were used without any further purification.

\subsection{Characterization of Nanocomposite Films}

Different techniques were performed to characterize the X-irradiated PVA/NBT film labels. The comparison between unirradiated films and those exposed to various Xradiation doses was studied to evaluate the effectiveness of the developed film dosimeters.

Virgin and X-irradiated PVA/NBT nanocomposite films were chemically characterized using FTIR spectrophotometric analysis (spectrophotometer Agilent tech with Gladi-ATR, USA). The ATR (attenuated total reflection) solid surface mode was used to carry out the different spectra. FTIR spectra were recorded from 4000 to $500 \mathrm{~cm}^{-1}$ with 20 scans and a resolution of $4 \mathrm{~cm}^{-1}$.

UV-vis absorption spectra of the different film labels were obtained using a UV-vis spectrophotometer (Shimadzu, UV-2501PC, Kyoto, Japan) in a range from 200 to $700 \mathrm{~nm}$.

X-ray diffraction patterns were recorded using X-ray Diffractometer PW 1720 (Philips) with $2 \theta$ varying from $10^{\circ}$ to $40^{\circ}$ and a step size of $0.01^{\circ}$. X-ray generator was of PW 1850 was exploited as a source of radiation and was equipped with a copper tube. A nickel filter was used to generate the monochromatic radiation.

SEM analyses were performed to study the surface morphology of the PVA/NBT nanocomposite films. Micrographs were obtained using Scanning Electron Microscopy (JEOL JSM-5400 LV, JEOL Ltd., Akishima, Tokyo Japan). Analysis was realized at $5 \mathrm{kV}$ of acceleration voltage and under varied magnifications from 100 to $2000 \times$. Surface conductivity of analyzed films was improved by applying a sputter coating with a fine gold layer prior to examination.

The spectrocolorimitric study of the PVA/NBT films before and after irradiation was accomplished via a spectrocolorimeter 3NH YD5010 within the visible spectrum at 39 wavelengths with $10 \mathrm{~nm}$ interval from $380 \mathrm{~nm}$ to $780 \mathrm{~nm}$. The K/S (color strength) values were determined using the Kubelka-Munk equation (Equation (1)) [37].

$$
\left(\frac{K}{S}\right)_{\lambda}=\frac{\left(1-R_{\lambda}\right)^{2}}{2 \times R_{\lambda}}
$$

where $K$ and $S$ are the absorption and scattering coefficients, respectively, and $R_{\lambda}$ is the spectral reflectance of the dyed fabric at $\lambda \max [38]$

CIELab coordinates of colored PVA/NBT films $\left(\mathrm{L}^{*}, \mathrm{a}^{*}, \mathrm{~b}^{*}\right)$ and the total color difference $(\triangle \mathrm{E})$ were measured under 10 degrees standard observer and D65 standard illuminant. 
Where $L^{*}$ describes lightness, $a *$ represents redness-greenness, $b^{*}$ represents yellownessblueness $[39,40]$.

The following Equation (2) allowed the $\Delta \mathrm{E}$ according to the different color coordinates:

$$
\Delta \mathrm{E}=\sqrt{\left(\mathrm{L}^{*}-\mathrm{L}_{0}\right)^{2}+\left(\mathrm{a}^{*}-\mathrm{a}_{0}\right)^{2}+\left(\mathrm{b}^{*}-\mathrm{b}_{0}\right)^{2}}
$$

where $\left(\mathrm{L}^{*}, \mathrm{a}^{*}, \mathrm{~b}^{*}\right)$ and $\left(\mathrm{L}_{0}, \mathrm{a}_{0}, \mathrm{~b}_{0}\right)$ are the color coordinates for the unirradiated and irradiated PVA/NBT films respectively. The average limit of the total color difference between two color points is the value above which the human eye cannot differentiate. Many limits depending mainly on color saturation have already been published in the literature [41,42].

\subsection{Preparation of PVA/NBT Nanocomposite Films}

PVA/NBT film samples were prepared via a simple cast method. A bulk Polyvinyl alcohol solution was prepared by dissolving $5 \mathrm{~g}$ of PVA in $100 \mathrm{~mL}$ of Milli-pure water. The solution was then kept in continuous stirring for $2 \mathrm{~h}$ at $80^{\circ} \mathrm{C}$. The obtaining homogenous solution was then cooled to ambient temperature. A prepared solution of NBT (0.04 g) dissolved in $10 \mathrm{~mL}$ of ethanol was added to the PVA solution. The mixing solution was stirred at ambient temperature for $1 \mathrm{~h}$. Film labels were casted by pouring $20 \mathrm{~mL}$ of the prepared solution onto each glass Petri plate using a graduated syringe. Films were then set to dry in darkness at room temperature for $72 \mathrm{~h}$. Uniformly dried transparent films were peeled out of the Petri dishes. The average thickness of the prepared films was then measured using a thickness gauge and was around $100 \mu \mathrm{m}$. Films were finally cut into small square-shaped pieces with $2 \mathrm{~cm}$ on the side and stored in sealed black envelopes in dark to avoid light degradation and to achieve a thermal equilibrium before investigations.

Films were finally exposed to different radiation doses using a digital $\mathrm{X}$-ray fluoroscopic machine model (GE, healthcare, model Al01CII, 2011-German, Chicago, IL, USA). This machine was adjusted depending on the exposure technique factors $(\mathrm{kVp}=60$, $\mathrm{mAs}=16$ and at $100 \mathrm{~cm}$ ) to produce exposure doses of $\mathrm{x}, \mathrm{y}, \mathrm{z}$ mGy. The system was calibrated and ascertained by an ionization chamber to produce the relevant doses.

\section{Results and Discussion}

\subsection{Post-Irradiation Stability}

PVA/NBT-made films exposed to a dose of $20 \mathrm{mGy}$ were stored in dark and light at room temperature in the laboratory. Films were stored for 30 days and the absorbance was measured during varied intervals of storage time at $352 \mathrm{~nm}$. Figure 1 shows the variation of the absorbance capacity according to the time of storage after $\mathrm{X}$-irradiation of the PVA/NBT nanocomposite films.

Results in this figure revealed the good stability of the films for the different periods of storage. The excellent stability was confirmed for both films stored in dark and in light, until the end of the storage period of 30 days. The studied stability upon storage period and conditions was excellent and efficient compared to other dosimeter using PVA and NBT in form of a solution or gel $[43,44]$ which, showed weak stability especially when stored under light. This could be explained by the casting in form of the film allowing more crystalline properties. 


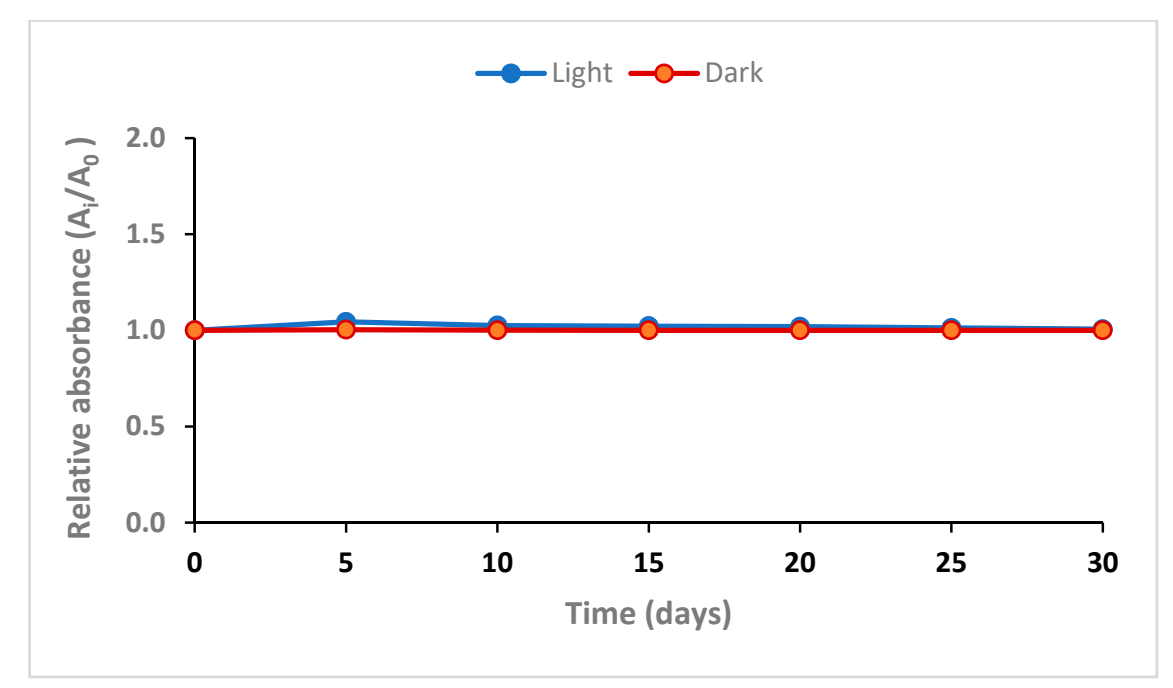

Figure 1. Post-irradiation stability of PVANBT films stored in dark and light at room temperature, $\lambda \max =430 \mathrm{~nm}$.

\subsection{Direct Percepted Color Effect after Irradiation}

The exposure of film nanocomposite samples of PVA dopped NBT to X-irradiation from 0 to $20 \mathrm{mGy}$ resulted in a clear change in color even with low doses (Figure 2). The change in color, from transparent colorless for PVA film to clear yellow for unirradiated PVA/NBT and to yellowish-brown gradually after X-irradiation, confirmed the high sensitivity of the made nanocomposite films to low radiation doses (at the mGy scale). The formation of hydrazine due to the reduction of the formazan may be the consequence of the change in color of the films $[45,46]$. The further studies presented in the following will show the effect of $\mathrm{X}$-irradiation on other parameters.

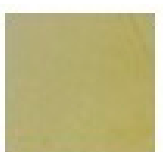

$0 \mathrm{mGy}$

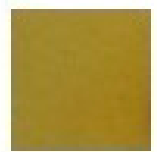

$2 \mathrm{mGy}$

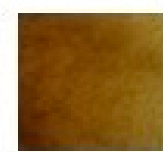

$4 \mathrm{mGy}$

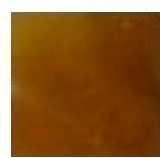

$10 \mathrm{mGy}$

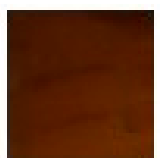

$20 \mathrm{mGy}$

Figure 2. Visual color change of PVA/NBT films before and after exposure to varying doses of $\mathrm{X}$-radiations.

\subsection{UV/Visible Absorption Spectra}

Figure 3 presents the UV-vis absorption spectra of both PVA control film and those irradiated with the different $\mathrm{X}$-ray doses. In the case of the PVA film which is transparent and colorless, there is no absorption peak in the visible region. The film is seen to become yellowish-brown gradually after X-irradiation. Results in Figure 3 show one sharp band with maximum absorption at $430 \mathrm{~nm}$. The absorption capacity of these bands increased according to the augmentation of the applied doses. The gradual increase noted in the broadening peak with the absorbed dose is related to the reduction of NBT2+ to monoformazan (MF+) then to a stable hydrophobic di-formazan (DF) structure under the effect of the applied irradiation $[47,48]$. The region of maximum absorption is violet/blue in color which is ascribed to yellow/orange as a complementary color. Therefore, the visual observation in color change presented previously is confirmed via the UV-spectroscopic analysis by observation of the absorption peak at $430 \mathrm{~nm}$. Furthermore, the absorption maximum was shifted gradually with the increasing dose from 430 to $450 \mathrm{~nm}$ (in the case of $20 \mathrm{mGy}$ dose). This was probably due to the more pronounced reduction of formazan for the NBT and the appearance of the di-formazan product. 


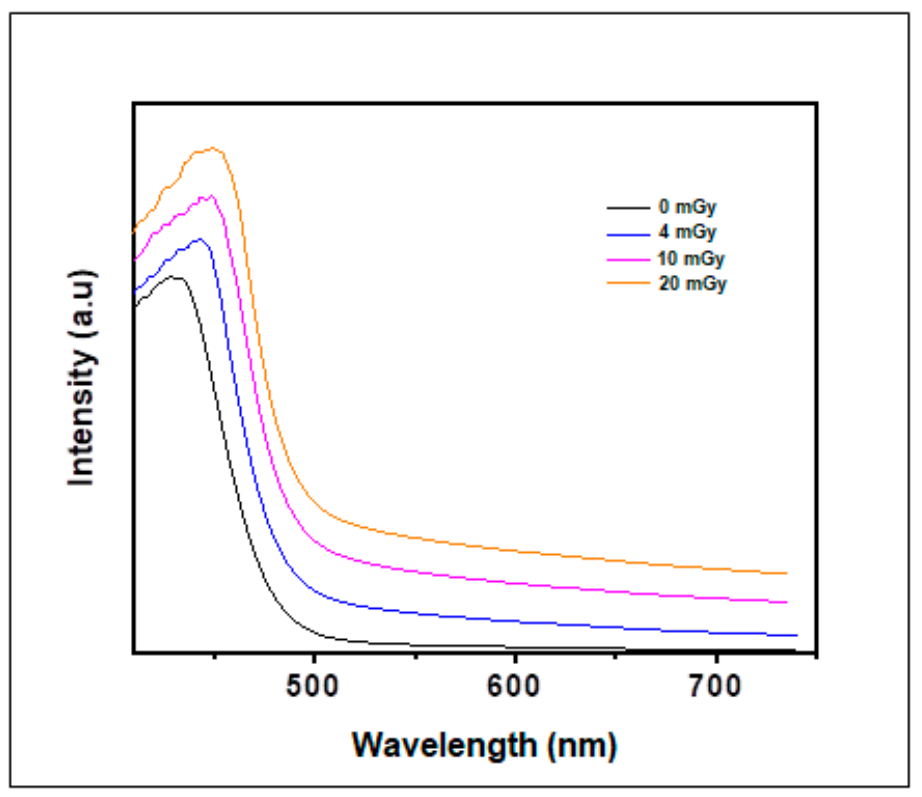

Figure 3. Absorbance spectra of PVA/NBT nanocomposite films before and after X-irradiation at varying doses.

\subsection{Response Curve}

Figure 4 shows the response curve of the nanocomposite PVA/NBT films exposed to different $\mathrm{X}$-ray doses. The response curves were established in terms of change in absorbance per unit thickness, $\Delta \mathrm{A} \cdot \mathrm{mm}^{-1}$ versus the absorbed dose, where $\Delta \mathrm{A}=\mathrm{A} 0-\mathrm{Ai}$, $\mathrm{A} 0$ and $\mathrm{Ai}$ are values of absorbance for the unirradiated and irradiated film respectively at $430 \mathrm{~nm}$. The resulting curve shows a linear increase in absorbance as a function of the increase in X-ray doses with $\mathrm{R}=0.998$ as the coefficient of linear regression. This result is very important in the application of the PVA/NBT synthesized films as dosimeters of high sensitivity, in particular at very low radiation doses.

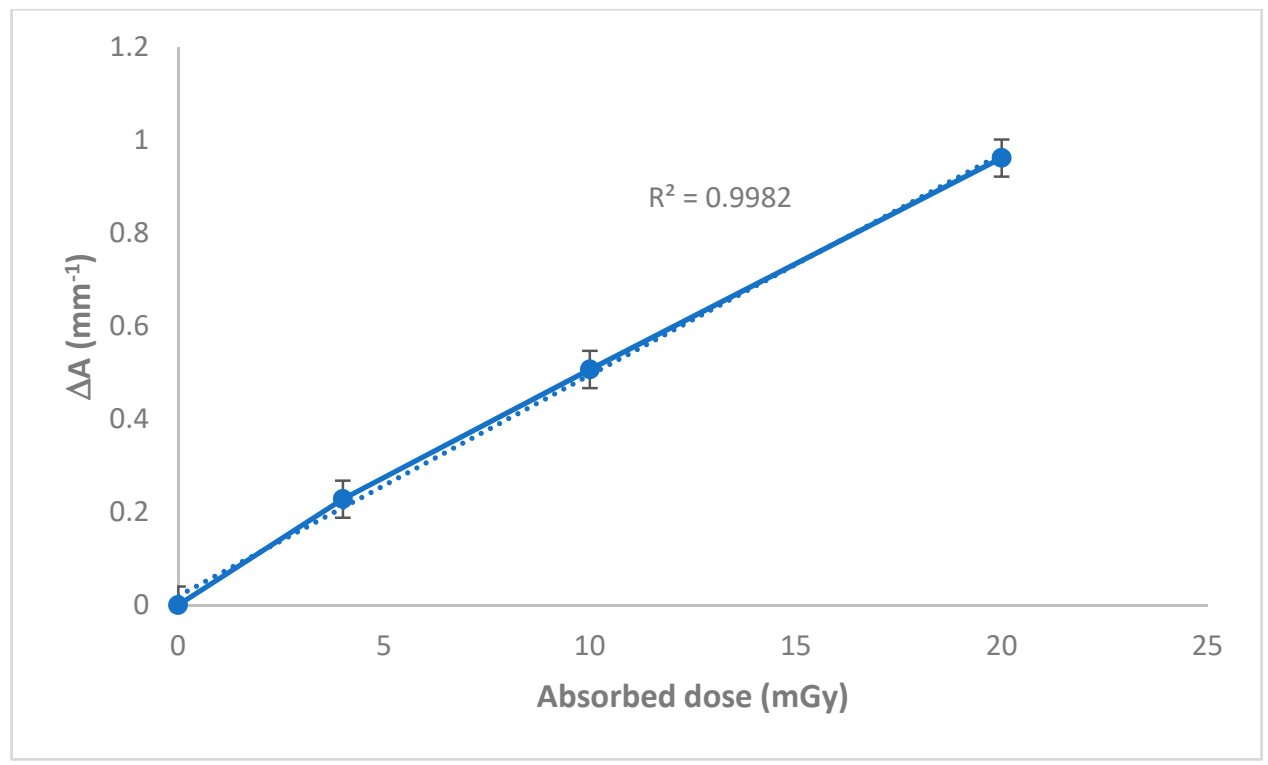

Figure 4. Dose-response curve based on UV-Vis absorption capacities at $\lambda$ max for PVA/NBT films exposed at various $\mathrm{X}$-ray doses. 


\subsection{FTIR Analysis}

The reduction of colorless to slightly yellowish tetrazolium salts using reducing agents as ionizing radiations produces a deeply colored mixture of formazan structures. Formazans exist in multiple conformers as tautomers and stereoisomers make the investigation analysis of their physical and chemical properties more complicated [49].

As explained above, the effect of the applied irradiation could be assigned by the transformation of the formazan structure to the other reduced structures. FTIR spectroscopy characteristics for formazans are the $\mathrm{C}=\mathrm{N}, \mathrm{N}-\mathrm{H}$ and $\mathrm{N}=\mathrm{N}$ absorption bands. Possible open structures after reduction show higher frequencies for these bands, due to the loss of resonance stabilization of the six-membered chelate ring. Figure 5 shows the different FTIR spectra of PVA, unirradiated PAV/NBT and irradiated PVA/NBT films with various X-ray doses. A characteristic infrared spectrum for PVA casted film is presented in Figure 5.

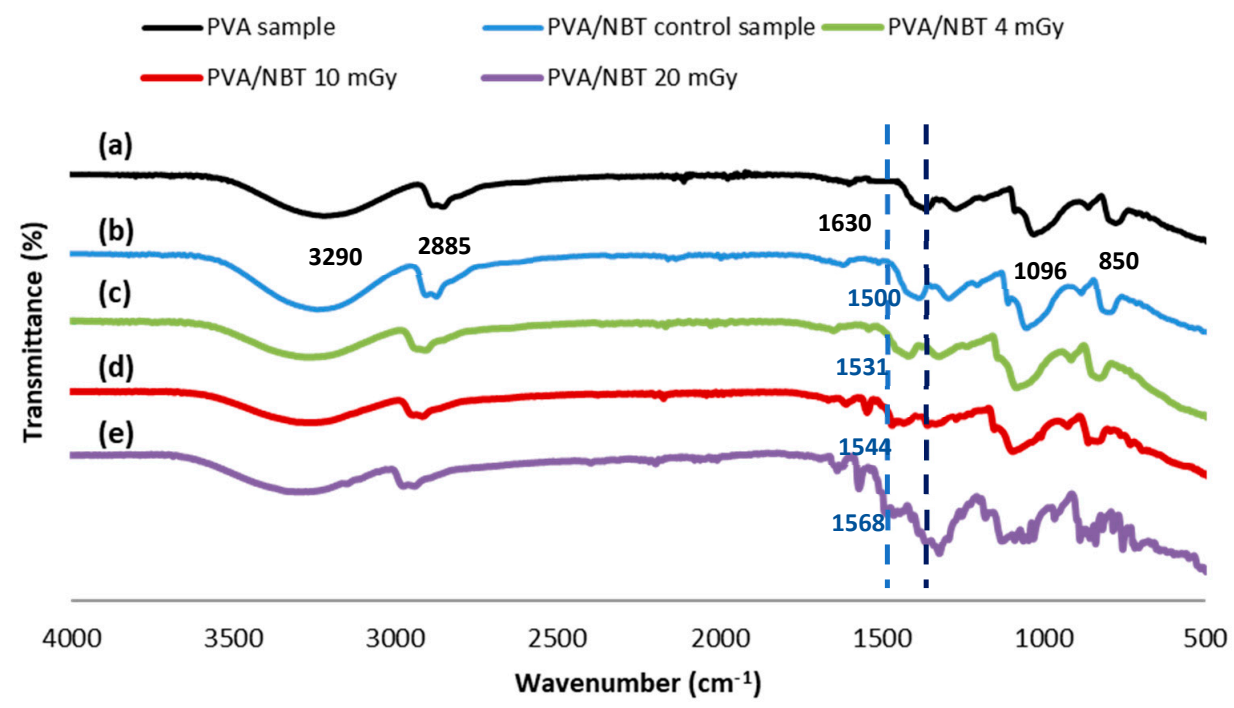

Figure 5. FTIR spectra of PVA film (a), unirradiated PVA/NBT film (b) and the X-irradiated PVA/NBT films receiving different doses; 4 mGy (c), $10 \mathrm{mGy}$ (d) and $20 \mathrm{mGy}(\mathbf{e})$.

The different typical absorption peaks and their referring chemical groups are summarized in Table 1.

Table 1. FTIR attribution bands of PVA control film.

\begin{tabular}{cccc}
\hline FTIR Bands $\mathbf{( \mathbf { c m } ^ { - 1 } )}$ & Attribution & Assignment & Reference \\
\hline 850 & C-H stretching & PVA backbone & {$[50]$} \\
916 & CH rocking & PVA backbone & {$[50,51]$} \\
1096 & C-O stretch vibration & PVA acetyl group & {$[50]$} \\
1141 & C-O-C stretch & Polysaccharide's pyranose & {$[50-52]$} \\
1630 & C-OH bending vibration & PVA hydroxyl group & {$[53]$} \\
$2850-2893$ & C-H stretch vibration & PVA backbone & {$[54]$} \\
3290 & OH stretch vibration & PVA hydroxyl group & {$[54]$} \\
\hline
\end{tabular}

A new peak appeared after the addition of NBT in the PVA film, centered at $1505 \mathrm{~cm}^{-1}$ referring to the $\mathrm{C}=\mathrm{N}$ stretching band which was ascribed to the formazan chelates $[55,56]$. This absorption characteristic peak revealed a gradual shifting according to the increased applied doses. In addition, the intensity of the peak increased with the X-ray doses. Another characteristic peak appeared at $1397 \mathrm{~cm}^{-1}$ referring to the $\mathrm{N}=\mathrm{N}$ stretch vibration for the reduced formazan structure [57]. This peak became more intense and shifted gradually with the increase of the X-radiation doses. Therefore, the FTIR performed characterization revealed well the stability of the PVA structure upon low X-ray doses while no chemical 
modification in the PVA characteristic groups (no scission in the main chain or removing of $\mathrm{OH}$ groups were detected). However, the effect of applied radiation appeared clearly on the nanocomposite PVA/NBT inducing some chemical transformations in the NBT structure.

\subsection{X-ray Diffraction Study}

The X-irradiation effect could be confirmed by the detection of induced changes in the crystallinity of PVA/NBT composite films. X-ray diffraction analysis was performed to evaluate the changes in crystallinity illustrated in the XRD patterns before and after $\mathrm{X}$-radiation exposure of the made films to different doses. Figure 6 shows X-ray diffractograms for control and X-irradiated PVA/NBT nanocomposite films at various doses. Control PVA/NBT film exhibited a typical peak centered at $2 \theta=19^{\circ}$, which is ascribed to diffraction from a mixture of planes (101) and (101) [58]. XRD patterns showed a significant decrease of the peak intensity at $2 \theta=19^{\circ}$ from control to X-irradiated films with $20 \mathrm{mGy}$. Furthermore, the results revealed the presence of two characteristic peaks on the diffractogram of the control film at $2 \theta=14$ and $17^{\circ}$. These peaks were assigned to the diffraction from (100) and (001) planes of PVA. We remarked on the disappearance of the two last-mentioned peaks after the X-irradiation of the PVA/NBT film. The peak at $2 \theta=41.06^{\circ}$ also corresponds to the PVA crystalline phase [59]. The different recorded changes in the intensity of the various peaks reveal that a structural rearrangement occurred after irradiation.

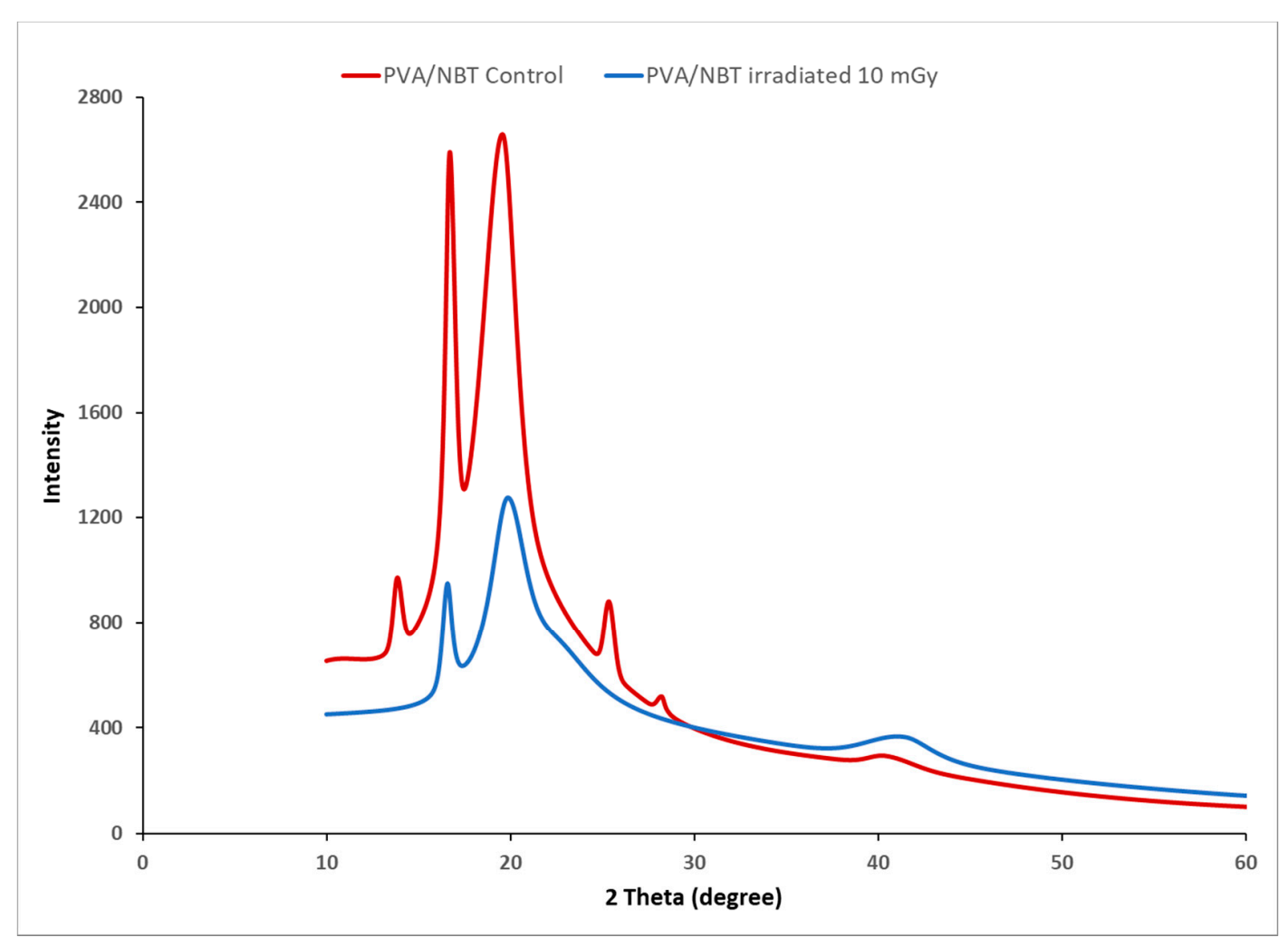

Figure 6. X-ray diffraction patterns of control and irradiated PVA/NBT films.

\subsection{SEM Morphological Analysis}

Morphological SEM analysis of control and irradiated PVA/NBT films was performed to evaluate the effect of the low X-ray doses on the surface morphology of the exposed samples. Figure 7 revealed for the PVA/NBT unirradiated film a smooth and homogeneous appearance with good structural integrity and crack-free states. The same observations were noted with the PVA films [60]. This obtained surface morphology showed the high compatibility of the two mixed compounds (PVA and NBT) and a compact structure lacking phase separation. After X-irradiation of the PVA/NBT films, we noted some fluke- 
like structures with the appearance of globules and many surface stripes. The various modifications and changes on the surface morphology of treated films became more intense with the increase of the $\mathrm{X}$-ray applied dose. The clear change in surface morphology after irradiation revealed the high sensitivity of the PVA/NBT prepared films and their effective application as dosimeters for low radiation, finding their interest in various medical diagnostic applications.
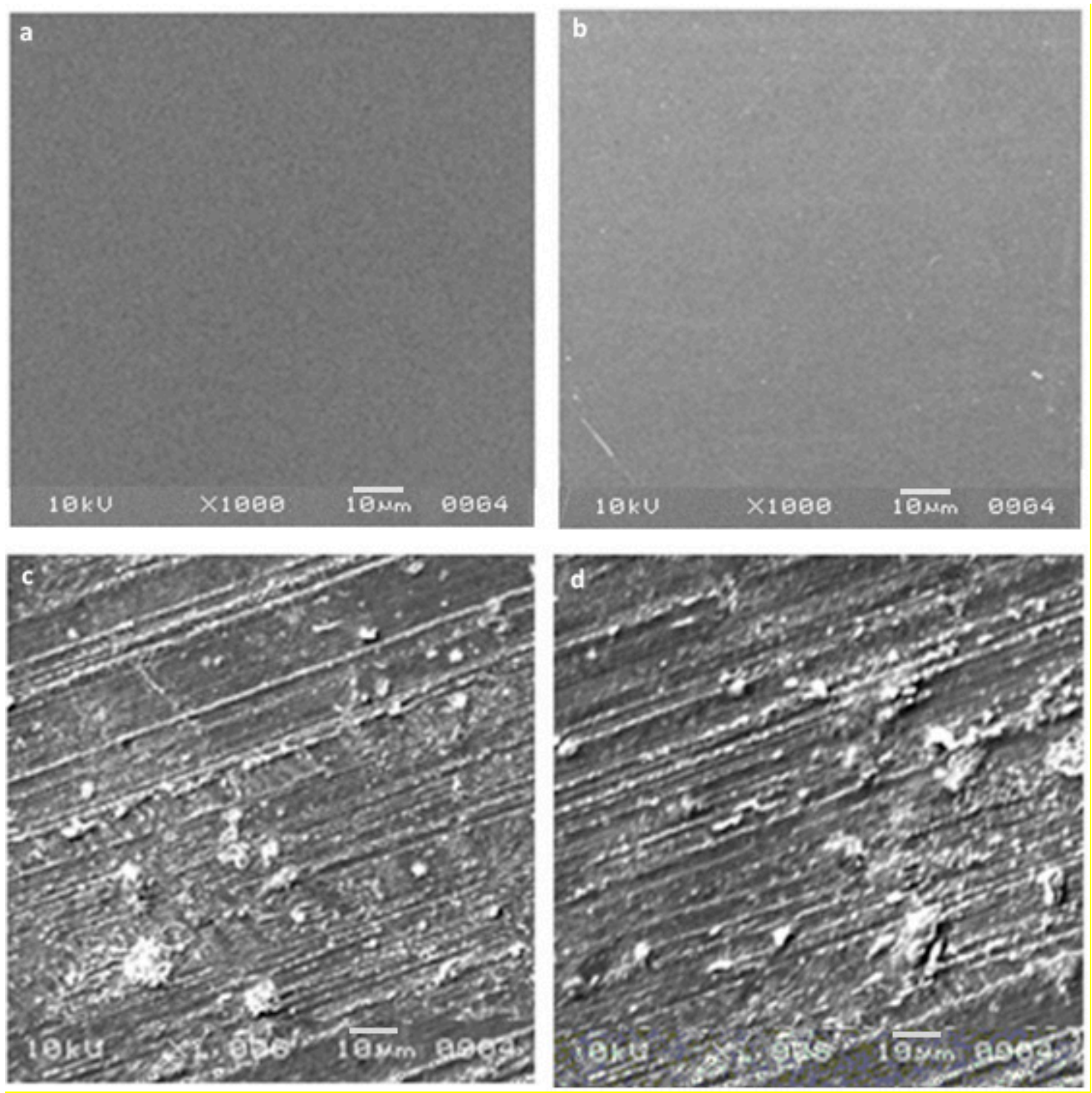

Figure 7. Scanning electron microscopy (SEM) morphologies of pure PVA film (a), unirradiated PVA/NBT (b) and irradiated PVA/NBT films with $10 \mathrm{mGy}$ (c) and $20 \mathrm{mGy}(\mathbf{d})$.

\subsection{Colorimetric Study}

Change in color shade or intensity is a very important practical property for efficient dosimeters. A colorimetry study was performed to evaluate and quantify the color deviation of the PVA/NBT films after their exposure to different low radiation doses. The mean deviation of the CIELab coordinates $\mathrm{L}^{*}, \mathrm{a}^{*}, \mathrm{~b}^{*}$, the $\Delta \mathrm{E}$ (total color difference) and the color strength $(\mathrm{K} / \mathrm{S})$ values for the unirradiated and the irradiated PVA/NBT-made films are summarized in Table 2. 
Table 2. Mean deviation of the CIELab coordinates $L^{*}, a^{*}, b^{*}$, the $\Delta E$ and $K / S$ values for unirradiated and X-irradiated PVA/NBT films from 4 to $20 \mathrm{mGy}$.

\begin{tabular}{cccccc}
\hline Sample Dose & $\mathbf{L}^{*}$ & $\mathbf{a}^{*}$ & $\mathbf{b}^{*}$ & $\boldsymbol{\Delta E}$ & $\mathbf{K} / \mathbf{S}$ \\
\hline 0 & 41.71 & 0.92 & 13.34 & & 3.4 \\
4 & 43 & 1.25 & 14.44 & 3.508 & 3.63 \\
10 & 44.9 & 1.72 & 16.27 & 5.793 & 3.89 \\
20 & 47.86 & 2.51 & 18.83 & 9.528 & 4.29 \\
\hline
\end{tabular}

Figure 8a-c shows the variation of the CIELab coordinates as a function of the radiation dose applied to the PVA/NBT films. $L^{*}$ decreased with increasing doses, this indicates that the color of the films has become darker. However, $\mathrm{a}^{*}, \mathrm{~b}^{*}$ values increased with doses so the films became more reddish and more bluish. We remarked for all these parameters a linear variation with a high correlation of $\mathrm{R}=0.99$. The linear dependence of the different color coordinates according to the increased applied radiation dose allows each color's coordinate index $\mathrm{a}^{*}, \mathrm{~b}^{*}$ and $\mathrm{L}^{*}$ to be investigated independently as a dosimetry index in the low dose range from 0 to $20 \mathrm{mGy}$. In addition, Figure $8 \mathrm{~d}$ revealed the increase of the total color difference $\Delta \mathrm{E}$ values with the $\mathrm{X}$-rays applied doses. We remarked also a linear change of the calculated $\Delta \mathrm{E}$ according to increased radiation doses. The same was observed for the color intensity or color strength parameter $\mathrm{K} / \mathrm{S}$, which increased linearly with increasing $\mathrm{X}$-ray doses (Figure 8e). The colorimetry study revealed the importance of the made nanocomposite PVA/NBT film to be applied as an efficient irradiation indicator and its potential application as a new dosimetric system in the field of X-ray diagnostic radiology.
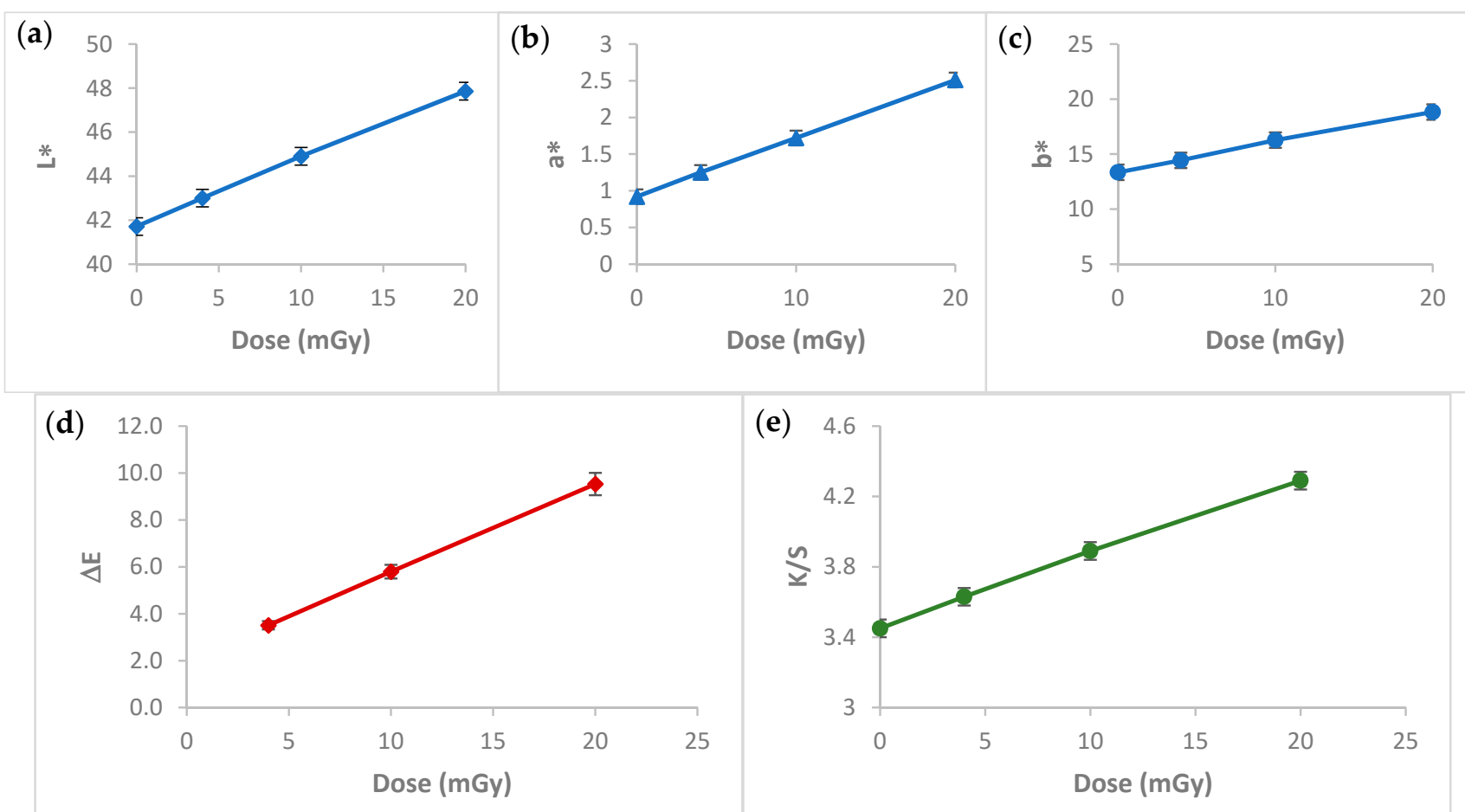

Figure 8. Hunter's color parameters: (a) lightness $L^{*},(\mathbf{b})$ redness-greenness axis a*, (c) yellowness-blueness axis $b^{*}$, (d) total color difference $\Delta \mathrm{E}$ and (e) color strength $\mathrm{K} / \mathrm{S}$ values for PVA/NBT films irradiated from 4 to $20 \mathrm{mGy}$.

\section{Conclusions}

Assessment of the X-ray dose to the patient is an essential aspect of the optimization process in X-ray diagnostic radiology. Therefore, finding an effective dosimetric system for low radiations in X-ray diagnostic radiology is a great challenge nowadays. The prepared 
PVA/NBT nanocomposite film showed high sensitivity upon various chemical, physical, morphological and colorimetrical characterizations after its exposure to increased low doses of X-radiations. Indeed, the results showed a gradual increase in the absorption capacity of the made PVA/NBT films with increased applied doses. This was related to the reduction of NBT+2 to mono-formazan configuration then to a more stable hydrophobic di-formazan structure under the effect of the applied irradiation. The resulting response curve based on UV-Vis absorptions revealed a linear increase in absorbance with the augmentation of the $\mathrm{X}$-ray low doses. The FTIR chemical characterization confirmed the presence of the effect of applied radiations on the nanocomposite PVA/NBT via the apparition of new bands ascribed to the chemical transformations in the NBT structure. X-ray diffraction analysis revealed clear changes in crystallinity illustrated in the XRD patterns after irradiation of the made films. The different recorded changes in the intensity of the various peaks are due to a structural rearrangement that occurred after irradiation. SEM analysis showed a clear morphological modification of PVA/NBT films after irradiation showing their high sensitivity upon very low $X$-radiations. In addition, the prepared PVA/NBT films exhibited excellent pre- and post-irradiation stability in dark and light from 5 to 30 days after radiation exposure. More important results were established with the colorimetry study since a clear visual change in color appears after irradiation treatment. This color change was evaluated quantitively by determining the different colorimetry coordinates, the total color difference and the color strength. All these parameters were showed to be increased linearly with increasing X-ray doses. The different characterization analysis confirmed the high sensitivity of the prepared films upon very low X-ray doses (in the scale of mGy). Furthermore, they revealed the practical efficiency of this nanocomposite PVA/NBT film to be applied as an effective irradiation indicator and its potential application as a new dosimetric system for routine diagnostic medical process control.

Author Contributions: Data curation, S.A., Y.E.-G. and M.A.A.O.; Formal analysis, S.A., Y.E.-G. and M.A.A.O.; Investigation, S.A., Y.E.-G.; Methodology, Y.E.-G., S.A.; Project administration, S.A. and Y.E.-G.; Software, S.A. and Y.E.-G.; Supervision, S.A.; Validation, S.A. and Y.E.-G.; Writing-original draft, S.A., Y.E.-G.; Writing-review and editing, Y.E.-G. All authors have read and agreed to the published version of the manuscript.

Funding: The authors gratefully acknowledge Qassim University, represented by the Deanship of Scientific Research, on the financial support for this research under the number 5677-cos-2019-2-2-I, during the academic year $1440 \mathrm{AH} / 2019 \mathrm{AD}$.

Institutional Review Board Statement: Not applicable.

Informed Consent Statement: Not applicable.

Conflicts of Interest: The authors declare no conflict of interest.

\section{References}

1. Miroshnichenko, S.; Timofeeva, V.; Permyakova, E.; Ershov, S.; Kiryukhantsev-Korneev, P.; Dvořaková, E.; Shtansky, D.V.; Zajíčková, L.; Solovieva, A.; Manakhov, A. Plasma-Coated Polycaprolactone Nanofibers with Covalently Bonded Platelet-Rich Plasma Enhance Adhesion and Growth of Human Fibroblasts. Nanomaterials 2019, 9, 637. [CrossRef]

2. El-Ghoul, Y.; Ammar, C.; El-Achari, A. New polymer based modified cyclodextrins grafted to textile fibers; characterization and application to cotton wound dressings. Int. J. Appl. Res. Text. 2014, 2, 11-21.

3. Salah, F.; El-Ghoul, Y.; Alminderej, F.M.; Golli-Bennour, E.E.; Ouanes, O.; Maciejak, M.; Jarroux, N.; Majdoub, H.; Sakli, F. Development, characterization, and biological assessment of biocompatible cellulosic wound dressing grafted Aloe vera bioactive polysaccharide. Cellulose 2019, 26, 4957-4970. [CrossRef]

4. Alminderej, M.F.; El-Ghoul, Y. Synthesis and study of a new biopolymer-based chitosan/hematoxylin grafted to cotton wound dressings. J. Appl. Polym. Sci. 2019, 136, 47625. [CrossRef]

5. El-Ghoul, Y. Biological and microbiological performance of new polymer-based chitosan and synthesized aminocyclodextrin finished polypropylene abdominal wall prosthesis biomaterial. Text. Res. J. 2020, 90, 2690-2702. [CrossRef]

6. Raouafi, A.; Daoudi, M.; Jouini, K.; Charradi, K.; Hamzaoui, A.H.; Blaise, P.; Hosni, F. Effect of gamma irradiation on the color, structure and morphology of nickel-doped polyvinyl alcohol films: Alternative use as dosimeter or irradiation indicator. Nucl. Instrum. Methods Phys. Res. Sect. B Beam Interact. Mater. At. 2018, 425, 4-10. [CrossRef] 
7. Susilawati, S.; Prayogi, S.; Arif, M.F.; Ismail, N.M.; Bilad, M.R.; Asy'ari, M. Optical Properties and Conductivity of PVA-H3PO4 (Polyvinyl Alcohol-Phosphoric Acid) Film Blend Irradiated by $\gamma$-Rays. Polymers 2021, 13, 1065. [CrossRef]

8. Harahap, M.; Widodo, P.; Priasetyono, Y.; Listyarini, A.; Djuhana, D.; Imawan, C.A. Simple gamma dosimeter using a film label made of polyvinyl alcohol and bark of Peltophorum ferrugineum extract. IOP Conf. Ser. Mater. Sci. Eng. 2019, $496,012041$. [CrossRef]

9. Ezzell, G.A.; Galvin, J.M.; Low, D.; Palta, J.R.; Rosen, I.; Sharpe, M.B.; Xia, P.; Xiao, Y.; Xing, L.; Yu, C.X. Guidance document on delivery, treatment planning, and clinical implementation of IMRT: Report of the IMRT subcommittee of the AAPM radiation therapy committee. Med. Phys. 2003, 30, 2089-2115. [CrossRef]

10. Butson, M.J.; Yu, P.K.; Cheung, T.; Metcalfe, P. Radiochromic film for medical radiation dosimetry. Mater. Sci. Eng. R Rep. 2003, 41, 61-120. [CrossRef]

11. Wilcox, E.E.; Daskalov, G.M. Evaluation of GAFCHROMIC ${ }^{\circledR}$ EBT film for CyberKnife ${ }^{\circledR}$ dosimetry. Med. Phys. 2007, 34, 1967-1974. [CrossRef]

12. Lemoigne, Y.; Caner, A. Radiotherapy and Brachytherapy; Springer Science \& Business Media: New York City, NY, USA, 2009.

13. Vergote, K.; Deene, Y.D.; Duthoy, W.; Gersem, W.D.; Neve, W.D.; Achten, E.; Wagter, C.D. Validation and application of polymer gel dosimetry for the dose verification of an intensity-modulated arc therapy (IMAT) treatment. Phys. Med. Biol. 2004, 49, 287-305. [CrossRef]

14. Wagter, C.D. The ideal dosimeter for intensity modulated radiation therapy (IMRT): What is required? J. Phys. Conf. Ser. 2004, 3, 002. [CrossRef]

15. Bekerat, H.; Devic, S.; DeBlois, F.; Singh, K.; Sarfehnia, A.; Seuntjens, J.; Lewis, D. Improving the energy response of external beam therapy (EBT) GafChromicTM dosimetry films at low energies ( $\leq 100 \mathrm{keV})$. Med. Phys. 2014, 41, 022101. [CrossRef]

16. Hermida-López, M.; Lüdemann, L.; Flühs, A.; Brualla, L. Technical Note: Influence of the phantom material on the absorbed-dose energy dependence of the EBT3 radiochromic film for photons in the energy range $3 \mathrm{keV}-18 \mathrm{MeV}$. Med. Phys. 2014, $41,112103$. [CrossRef]

17. Luxton, G.; Jozsef, G. Radial dose distribution, dose to water and dose rate constant for monoenergetic photon point sources from $10 \mathrm{keV}$ to $2 \mathrm{MeV}$ : EGS4 Monte Carlo model calculation. Med. Phys. 1999, 26, 2531-2538. [CrossRef] [PubMed]

18. Davidson, S.E.; Ibbott, G.S.; Prado, K.L.; Dong, L.; Liao, Z.; Followill, D.S. Accuracy of two heterogeneity dose calculation algorithms for IMRT in treatment plans designed using an anthropomorphic thorax phantom. Med. Phys. 2007, 34, 1850-1857. [CrossRef]

19. Arjomandy, B.; Tailor, R.; Anand, A.; Sahoo, N.; Gillin, M.; Prado, K.; Vicic, M. Energy dependence and dose response of Gafchromic EBT2 film over a wide range of photon, electron, and proton beam energies. Med. Phys. 2010, 37, $1942-1947$. [CrossRef] [PubMed]

20. Bolton, P.R.; Borghesi, M.; Brenner, C.; Carroll, D.C.; De Martinis, C.; Fiorini, F.; Wilkens, J.J. Instrumentation for diagnostics and control of laser-accelerated proton (ion) beams. Phys. Med. 2014, 30, 255-270. [CrossRef] [PubMed]

21. Devic, S. Radiochromic film dosimetry: Past, present, and future. Phys. Med. 2011, 27, 122-134. [CrossRef] [PubMed]

22. Nguyen, N.T.; Dao, T.H.; Truong, T.T.; Nguyen, T.M.T.; Pham, T.D. Adsorption characteristic of ciprofloxacin antibiotic onto synthesized alpha alumina nanoparticles with surface modification by polyanion. J. Mol. Liq. 2020, 309, 113150. [CrossRef]

23. Nifant'ev, I.; Shlyakhtin, A.; Komarov, P.; Tavtorkin, A.; Kananykhina, E.; Elchaninov, A.; Vishnyakova, P.; Fatkhudinov, T.; Ivchenko, P. In Vitro and In Vivo Studies of Biodegradability and Biocompatibility of Poly( $\varepsilon$ CL)-b-Poly(EtOEP)Based Films. Polymers 2020, 12, 3039. [CrossRef] [PubMed]

24. El-Ghoul, Y.; Alminderej, F.M. Bioactive and superabsorbent cellulosic dressing grafted alginate and Carthamus tinctorius polysaccharide extract for the treatment of chronic wounds. Text. Res. J. 2020, 91, 235-248. [CrossRef]

25. Habib, S.; Zavahir, S.; Abusrafa, A.E.; Abdulkareem, A.; Sobolčiak, P.; Lehocky, M.; Vesela, D.; Humpolíček, P.; Popelka, A. Slippery Liquid-Infused Porous Polymeric Surfaces Based on Natural Oil with Antimicrobial Effect. Polymers 2021, 13, 206. [CrossRef]

26. El-Ghoul, Y.; Salah, F.; Majdoub, H.; Sakli, F. Synthesis and study of drug delivery system obtained via $\beta$-cyclodextrin functionalization of viscose/polyester dressings. J. Ind. Text. 2017, 47, 489-504. [CrossRef]

27. Ghosh, M.; Halperin-Sternfeld, M.; Grinberg, I.; Adler-Abramovich, L. Injectable Alginate-Peptide Composite Hydrogel as a Scaffold for Bone Tissue Regeneration. Nanomaterials 2019, 9, 497. [CrossRef]

28. Weems, A.C.; Perez-Madrigal, M.M.; Arno, M.C.; Dove, A.P. 3D Printing for the Clinic: Examining Contemporary Polymeric Biomaterials and their Clinical Utility. Biomacromolecules 2020, 24, 1037-1059. [CrossRef] [PubMed]

29. Yang, R.; Chen, F.; Guo, J.; Zhou, D.; Luan, S. Recent advances in polymeric biomaterials-based gene delivery for cartilage repair. Bioact. Mater. 2020, 5, 990-1003. [CrossRef]

30. Kalai, S.N.; Shanmugarajan, T.S.; Uppuluri, V.N.V.A. Hydrogel based scaffolding polymeric biomaterials: Approaches towards skin tissue regeneration. J. Drug Deliv. Sci. Technol. 2020, 55, 101456. [CrossRef]

31. EL-Ghoul, Y.; Ammar, C.; Alminderej, F.M.; Shafiquzzaman, M. Design and Evaluation of a New Natural Multi-Layered Biopolymeric Adsorbent System-Based Chitosan/Cellulosic Nonwoven Material for the Biosorption of Industrial Textile Effluents. Polymers 2021, 13, 322. [CrossRef]

32. Moad, G.; Solomon, D.H. The Chemistry of Free Radical Polymerization, 1st ed.; Elsevier Science Ltd.: Oxford, UK, 1995. 
33. Mbhele, Z.; Sakmane, M.G.; Van Sittert, C.G.C.E.; Nedeljkovic, J.M.; Djoković, V.; Luyt, A.S. Fabrication and Characterization of Silver-Polyvinyl Alcohol Nanocomposites. Chem. Mater. 2003, 15, 5019-5024. [CrossRef]

34. Zhang, Z.; Han, M. Preparation and properties of nano-sized Ag and Ag2S particles in biopolymer matrix. J. Mater. Chem. Commun. 2003, 13, 641-645. [CrossRef]

35. Firth, A.V.; Haggata, S.W.; Khanna, P.K.; Williams, S.J.; Allen, J.W.; Magennis, S.W.; Cole-Hamilton, D.J. Production and luminescent properties of CdSe and CdS nanoparticle-polymer composites. J. Lumin. 2004, 109, 163-172. [CrossRef]

36. Wang, Y.; Wang, X.; Zhang, J.H.F.; Zhishen, M.O.; Jing, X.; Wnag, F.J. Morphological Study on Water-borne Conductive Polyaniline-Poly(ethylene oxide) Blends. J. Polym. Sci. Part B Polym. Phys. 2002, 40, 609-612. [CrossRef]

37. Lee, H.C. Introduction to Color Imaging Science; Cambridge University Press: New York City, NY, USA, 2005.

38. Kuehni, R.G. Color: An Introduction to Practice and Principles, 2nd ed.; John Wiley: Hoboken, NJ, USA, 2005.

39. Schanda, J. Colorimetry: Understanding the CIE System; John Wiley: Hoboken, NJ, USA, 2007.

40. Shams-Nateri, A. Effect of a standard colorimetric observer on the reconstruction of reflectance spectra of coloured fabrics. Coloration Technol. 2008, 124, 14-18. [CrossRef]

41. McGrath, J.R.; Beck, M.; Hill, M.E. Replicating Red: Analysis of ceramic slip color with CIELAB color data. J. Archaeol. Sci. Rep. 2017, 14, 432-438. [CrossRef]

42. Johnston, W.M.; Kao, E.C. Assessment of Appearance Match by Visual Observation and Clinical Colorimetry. J. Dent. Res. 1989, 68, 819-822. [CrossRef] [PubMed]

43. El Gohary, M.I.; Soliman, Y.S.; Amin, E.A.; Gawad, M.H.A.; Desouky, O.S. Effect of perchloric acid on the performance of the Fricke xylenol gel dosimeter. Appl. Radiat. Isot. 2016, 113, 66-69. [CrossRef] [PubMed]

44. Abdel-Fattah, A.A.; Beshir, W.B.; Hassan, H.M.; Soliman, Y.S. Radiation-induced coloration of nitro blue tetrazolium gel dosimeter for low dose applications. Radiat. Meas. 2017, 100, 18-26. [CrossRef]

45. Emi-Reynolds, G.; Kovacs, A.; Fletcher, J.J. Dosimetry characterization of tetrazolium violet-polyvinylalcohol films. Radiat. Phys. Chem. 2007, 76, 1519-1522. [CrossRef]

46. Pikaev, A.K.; Kriminskaya, Z.K. Use of tetrazolium salts in dosimetry of ionizing radiation. Radiat. Phys. Chem. 1998, 52, 555-561. [CrossRef]

47. Kovacs, A.; Baranyai, M.; Wojn!arovits, L.; Moussa, A.; Othman, I.; McLaughlin, W.L. Aqueous-ethanol nitro blue tetrazolium solutions for high dose dosimetry. Radiat. Phys.Chem. 1999, 55, 799-803. [CrossRef]

48. Moussa, A.; Baranyai, M.; Wojnárovits, L.; Kovács, A.; McLaughlin, W. Dosimetry characteristics of the nitro blue tetrazoliumpolyvinylalcohol film for high dose applications. Radiat. Phys. Chem. 2003, 68, 1011-1015. [CrossRef]

49. Bedada, T.G. Characterization of Tetrazolium Salts and Formazans using Computational Chemistry for Radiochromic Dosimetry. Electron. Thesis Diss. Repos. 2019, 6458, 1-113.

50. Gonzalez, J.S.; Ludueña, L.N.; Ponce, A.; Alvarez, V.A. Poly(vinyl alcohol)/cellulose nanowhiskers nanocomposite hydrogels for potential wound dressings. Mater. Sci. Eng. C 2014, 34, 54-61. [CrossRef]

51. Kenney, J.F.; Willcockson, G.W. Structure-Property relationships of poly(vinyl alcohol). III. Relationships between stereoregularity, crystallinity, and water resistance in poly(vinyl alcohol). J. Polym. Sci. Part. A-1 Polym. Chem. 1966, 4, 679-698. [CrossRef]

52. Olewnik-Kruszkowska, E.; Gierszewska, M.; Jakubowska, E.; Tarach, I.; Sedlarik, V.; Pummerova, M. Antibacterial Films Based on PVA and PVA-Chitosan Modified with Poly(Hexamethylene Guanidine). Polymers 2019, 11, 2093. [CrossRef]

53. Choo, K.; Ching, Y.C.; Chuah, C.H.; Julai, S.; Liou, N.-S. Preparation and Characterization of Polyvinyl Alcohol-Chitosan Composite Films Reinforced with Cellulose Nanofiber. Materials 2016, 9, 644. [CrossRef] [PubMed]

54. Zhao, L.; Mitomo, H.; Zhai, M.; Yoshii, F.; Nagasawa, N.; Kume, T. Synthesis of antibacterial PVA/CM-chitosan blend hydrogels with electron beam irradiation. Carbohydr. Polym. 2003, 53, 439-446. [CrossRef]

55. Tezcan, H. Synthesis and spectral properties of some bis-substituted formazans. Spectrochim. Acta Part A Mol. Biomol. Spectrosc. 2008, 69, 971-979. [CrossRef] [PubMed]

56. Sandorfy, C.; Lewis, J.W. Infrared absorption and resonance Raman scattering of photochromic triphenylformazans. Can. J. Chem. 1983, 61, 809-816.

57. Sigeikin, G.I.; Lipunova, G.N.; Pervova, I.G. Formazans and their metal complexes. Russ. Chem. Rev. 2006, 75, 885-900. [CrossRef]

58. Bhat, N.V.; Nate, M.M.; Kurup, M.B.; Bambole, V.A.; Sabharwal, S. Effect of $\gamma$-radiation on the structure and morphology of polyvinyl alcohol films. Nucl. Instrum. Methods Phys. Res. Sect. B Beam Interact. Mater. At. 2005, 237, 585-592. [CrossRef]

59. Eisa, W.H.; Abdel-Moneam, Y.K.; Shaaban, Y.; Abdel-Fattah, A.A.; Abou Zeid, A.M. Gamma-irradiation assisted seeded growth of Ag nanoparticles within PVA matrix. Mater. Chem. Phys. 2011, 128, 109-113. [CrossRef]

60. Chen, S.A.; Fang, W.G. Electrically conductive polyaniline-poly(vinyl alcohol) composite films: Physical properties and morphological structures. Macromolecules 1991, 24, 1242-1248. [CrossRef] 